О НЕОБХОДИМОСТИ СОВЕРШЕНСТВОВАНИЯ РЕГУЛИРОВАНИЯ ОБОРОТА СОВРЕМЕННЫХ ДИЗЕЛЬНЫХ ТОПЛИВ

Зоря Евгений Иванович, доцент кафедры нефтепродуктообеспечения и газоснабжения, РГУ нефти и газа (НИУ) имени

И.М. Губкина г. Москва

Лощенкова Ольга Валентиновна,

член подкомитета по моторным топливам ТПП РФ.

DOI: 10.31618/ESU.2413-9335.2018.3.57.27-30

\title{
ABOUT THE NEED TO IMPROVE REGULATION OF THE TURNOVER OF THE CURRENT
} DIESEL FUEL

Evgeniy I. Zorya - senior lecturer Gubkin Russian State University of Oil and Gas (NRU)

Olga V. Loshchenkova, Subcommittee on motor fuels,

\begin{abstract}
АННОтАЦИЯ. В работе проведен анализ нормативных требований отечественных и зарубежных стандартов к конкретному виду/типу современного дизельного топлива. Рассмотрена информация об эксплуатационных требованиях и декларируемых показателях качества, которые контролируются при движении топлива от НПЗ к потребителю. Отмечается, что новые высокоэкологичные ультранизкосернистые топлива ведут себя непредсказуемо по сравнению с более ранними продуктами и поэтому эти топлива требует не только определенного формулирования, но также дополнительного специфического обращения и контроля показателей качества.
\end{abstract}

ABSTRACT: The paper analyzes the regulatory requirements of domestic and foreign standards for a particular type/type of modern diesel fuel. The information about the operational requirements and declared quality indicators that are controlled by the movement of fuel from the refinery to the consumer is considered. It is noted that new high-ecological ultra-low-sulfur fuels behave unpredictably in comparison with earlier products and therefore these fuels require not only a certain formulation, but also additional specific treatment and quality control.

Ключевые слова: Показатели качества, оборот нефтепродуктов, ультранизкосернистое дизельное топливо, совместимость присадок

Keywords: Quality indicators, turnover of petroleum products, ultra-sour diesel fuel, compatibility of additives

В 2017 г. оборот дизельного топлива (ДТ) на внутреннем рынке РФ составил 33,1 млн тонн. На рост внутреннего потребления оказывает влияние дизелизация рынка потребления за счет легкового транспорта (в предыдущие периоды ДТ в основном потреблялось грузовой и внедорожной техникой). Новая автотранспортная техника требует новые классы топлива, обеспечивающие его эксплуатационные и экологические требования. Согласно требований ТР ТС 013/2011 и отчетам нефтегазовых компаний в РФ полностью осуществлен переход на класс 5 топлива с содержанием серы не более 10 ppm, который в мировой практике принято называть ULSD - ультранизкосернистое ДТ (в США дизельное дорожное топливо ULSD содержит не более 15 ppm серы)

В качестве базовых стандартов на ДТ в РФ выступает ГОСТ Р 52368-2005 (ЕН 590:2004) и межгосударственный ГОСТ 32511-2013 (модифицированный к EN 590:2009+ F1:2010), т.е. стандарты на ДТ ЕВРО. Кроме того нефтегазовые компании выпускают улучшенное, т.н. «брендовое» топливо по стандартам организаций. Дизельное топливо по ГОСТ 305-2013 «Топливо дизельное. Технические условия», заменивший ранее действующую версию ГОСТ 305-82 через АЗС не реализуется.

Современное дизельное топливо совсем не то, что производилось несколько лет назад. Ранее это был продукт ректификации нефти, прямогонный и

достаточно стабильный продукт без серьезных общих проблем деградации. С переходом на высокие экологические классы ДТ превратилось в экологически чистый топливный продукт, удовлетворяющий требованиям современного двигателестроения. Содержание серы в ДТ снизилось до 10 ppm. Углубление переработки с применением гидрокрекинга и гидродесульфуризации привело в появлению на рынке ДТ измененного углеводородного состава, а с ним появились и новые проблемы изменения качества при хранении. Глубокое обессеривание привело к изъятию из топлива сернистых соединений - естественных смазывающих компонентов, также сера в топливе была препятствием био- и грибкового роста. Ультранизкосернистое топливо потребовало компенсации утерянных свойств. Ведущие мировые двигателестроители изменили отношение к срокам хранения топлива, в частности Caterpillar рекомендует максимум 1 год с производства дистиллята при хранении в нормальных условиях (не выше $20^{\circ} \mathrm{C}$ ) дизельного топлива ULSD. При повышении температуры хранения до $30^{\circ} \mathrm{C}$ рекомендуется снижать срок хранения до 6 месяцев. В профильных изданиях отмечается увеличение асфальтенов в топливе [1]. Считается, что свыше 90\% органического мусора, засоряющего фильтры, составляют продукты деградации топлива. 
В отечественной же практике при выявлении претензий на качество ДТ в рознице (на АЗС) применяется общая формулировка «некачественное топливо» (от прямых потребителей), «фальсификат» и «несоответствующее нормативной документации» (из результатов проверок). Можно предположить, что первое - субъективное мнение, а второе/третье - объективные данные. Как показывают различные исследования, даже, если топливо соответствует паспортным требованиям, это еще не гарантия отсутствия жалоб со стороны потребителя. На качество товарного топлива, в т.ч. дизельного, влияют воздействия (естественная деградация ДТ) в период хранения и транспортировки конечному потребителю, поэтому необходимо сквозное поддержание требуемых показателей в цепочке:

НПЗ - транспорт и хранение при дистрибьюции (топливообеспечение) - отпуск на АЗС - поддержание чистоты топлива в баке потребителя (автомобиля).

Усовершенствованное оборудование впрыска топлива, разработанное по стандартам Euro V, предъявляет к топливу дополнительные эксплуатационные требования для использования в сложных схемах впрыска с давлением до 2000 бар и выше [2] Зазор между движущимися частями уменьшается, и при этом отложения будут иметь даже большее влияние на риск негативных последствий. Сама по себе проблема отложений на инжекторе не является новой, еще в 1980-х появились публикации в США на эту тему. Отложения на инжекторе вызывают естественное желание определить их состав и разработать превентивные меры. Проводились исследования на предмет добавок, которые могли бы такие отложения на инжектор предотвращать. Присадки, контролирующие управление отложениями включают различные подтипы присадок. Моющие, деэмульгаторы и стабилизаторы являются основными и обычно используются вместе для контроля образования отложений. С версии EN 590-2009, в техническую характеристику ДТ, в т.ч. и в РФ, теперь включается параметр окислительной стабильности “период индукции” (EN 15751) с минимальным пределом стабильности 20 часов. Показатель считается важной характеристикой для защиты автомобиля. Визуально топлива процессов ГК прозрачные и бесцветные, как вода. Потемнение - признак низкокачественного топлива за счет появления в нем продуктов старения или загрязнения, помутнение говорит о наличии в топливе эмульгированной воды.

Страны Евросоюза регулирует параметры дизельного топлива посредством Директивы 98/70/ЕС и EN 590:2013 и проводят контроль бензина и ДТ в розничной продаже с 2003 года с выпуском EU Fuel Quality Monitoring - Summary Report, используя стандарт EN 14274:2003, Fuel quality monitoring system (FQMS), и EN14275:2003 по порядку отбора проб. Такой контроль оказывает положительное влияние, так на 2013 г. отклонения по одному или нескольким показателям составило в 28 странах ЕС по ДТ из 14714 анализов проб ДТ по 6 основным показателям превышение выявлено в 1,1\% случаев (в 2011 г было выявлено 1,5\% случаев на 13718 анализов проб). В ДТ превышение от норматива по сере 10 ppm, составили 0,65\%. Превышение по дистилляционным характеристикам и плотности составили $0,12 \%$ и $0,03 \%$ соответственно. В США выявлено, что для обеспечения, требуемого содержания серы при отпуске 15 ppm, топливо должно выходить с завода около 6 ppm, т.е с запасом, т.к. сера при дистрибьюции накапливаются. Существуют рекомендации, препятствующие перекрестному загрязнению, когда в системе транспортировки и отпуска находится ULSD с серой 15 ppm и LSD - с 500 ppm (оба продукта реализуются через АЗС).

В развивающихся северных и восточных регионах РФ возрастает потребность не только зимнем, но и в арктическом дизельном топливе. Кроме ГОСТ 32511-2013 (модифицированный к $\mathrm{EN}$ 590:2009+F1:2010) имеется стандарт на топливо дизельное зимнее и арктическое депарафинированное ГОСТ Р 55475-2013.

Как показывает практика, нормативные требования далеко не всегда содержат необходимый объем требований для обеспечения эксплуатационных показателей.

Из мировой практики известно, что новые высокоэкологичные ULSD ведут себя непредсказуемо по сравнению с более ранними продуктами итопливо требует не только определенного формулирования, но также дополнительного специфического обращения и контроля. Значение ЦЧ=51, это требуемый минимум согласно техрегламента и EN 590. В The Worldwide Fuel Charter (пятое издание, сентябрь 2013 г.), приведено 5 категорий дизельного топлива, минимально требуемые показатели ЦЧ составляют 48, 51, 53, 55 в зависимости от категории, для топлив продвинутого эмиссионного контроля и топливной эффективности требования составляют значение 55. Компонент ДТ с установки гидрокрекинга является высокоцетановым, но таких установок в РФ пока мало, и коррекция с помощью присадок продолжает оставаться актуальной, а обеспечение показателей по ЦЧ и смазывающей способности требуют от отечественных производителей активного использования присадок, цетанповышающих и смазывающих. В случае корректировки ЦЧ присадками следует учитывать, что цетанповышающие присадки, применяемые отечественными НПЗ чувствительны к наличию воды в топливе.

В отличие от РФ в мире для корректировки ЦЧ и смазывающей способности применяется добавление биодизельных эфиров FAME (достаточным считается 1,5-2\%), применение которого в РФ разрешено техрегламентом, но производство FАME отсутствует и практика применения мало изучена. С 01.07.2016 г. действует межгосударственный стандарт ГОСТ 33131-2014 «Смеси биодизельного топлива В6-В20, Технические требования». Стандарт не является методикой смешения и обращения смесевых дизельных топлив, но содержит необходимые данные для производства смесевого дизельного топлива с использованием FAME. Такое топливо может являться частично регламентным, если 
содержание биоэфира не превышает разрешенное техрегламентом значение не более $7 \%$.

Значение показателя смазывающей способности варьируются в мировой практике, так, например, в рекомендациях Всемирной топливной хартии значение показателя указывается как 400 и 460 в зависимости от категории дизельного топлива (всего 5 категорий), лимит в ЕС составляет 460, а в США - свыше 500, в РФ принято значение 460.

В соответствии с п.4.1. ГОСТ 32511-2013 и п.5.1 ГОСТ 305-2013, топливо должно не только соответствовать требованиям стандарта, но топлива должны изготовляться по технологии и с присадками, которые применялись при изготовлении опытно-промышленных образцов и прошли испытания с положительными результатами. Данное требование, по сути, исключает замену присадок в процессе производства, если они не проходили испытания при постановке топлива на производство. Чем больше присадок вовлекается в пакет, тем сложнее оценить их взаимное влияние. К сожалению, в настоящее время в РФ не существует методики или программы, позволяющей оценить непосредственное взаимное влияние присадок с различными функциональными свойствами.

Некоторые присадки, такие как антиокислительные, добавляются на НПЗ еще до направления фракций насмешение товарного топлива. Другая группа, например моющие, относится к улучшению эксплуатационных свойств, т.е. придает топливам дополнительные свойства сверх требований спецификаций для создания «брендовых топлив». Моющие присадки входят в состав почти всех многофункциональных (полифункциональных) пакетов присадок, используемых для улучшения эксплуатационных характеристик топлив и должны вводиться в чистое базовое топливо на этапе максимально приближенном к отпуску топлива конечному потребителю на АЗС, поэтому имеется практика доведения топлива до состояния «брендовое» в условиях нефтебазы.

При хранении ДТ в условиях холодного климата имеет место расслоение топлива при хранении и нетипичное поведение топлива класса 5 по сравнению с классом 4 и ниже, что требует выработки новых подходов, как к методам формулирования, так и особенностям хранения. Температура помутнения (СР) топлива определяется как температура, при которой кристаллы становятся видимыми (диаметр превышает 0,5 мкм), образующими туманную или мутную плавающую завесу.ASTMD 2500. ASTM D2500 - 11 «Стандартный метод определения температуры помутнения нефтепродуктов» охватывает только нефтепродукты и биодизельные топлива, которые прозрачны в слое толщиной 40 мм и имеют температуру помутнения ниже $49^{\circ} \mathrm{C}$ другой метод -ISO 3015:1992 «Нефтепродукты. Определение точки помутнения».

При производстве зимних ДТ допускается использование депрессорных присадок посредством их введения в летнее дизельное топливо. Топливо ДЗп получаемое добавлением депрессорных приса- док к летнему дизельному топливу, можно использовать при температуре до $-15^{\circ} \mathrm{C}$ в автомобилях и до $-20^{\circ} \mathrm{C}$ в тракторах. Также были разработаны топлива ДЗп -25/-35, ДЗп-35/-45 и арктическое ДАп - с использованием депрессорно-диспергирующих присадок.

Без модификатора парафинов CFPР топлива (температура забивки холодного фильтра) обычно составляет около $3^{\circ} \mathrm{C}$ ниже температуры СР (температура помутнения). С модификатором парафинов ожидаемая разница будет больше. Спецификации ВР требуют, чтобы разница не превышала $8^{\circ} \mathrm{C}$.

Практика топливообеспечения показывает, что зимние ДТ, приготовленные смешением с керосинами или депрессорными присадками, в зимних условиях хранения могут расслаиваться на верхний прозрачный слой и нижний мутный, куда «уходит» кристаллическая фаза парафинов. Такое явление происходит в условиях, когда температура хранения становится ниже температуры помутнения. Считается, что стабильными являются топлива, у которых температура помутнения и температура предельной фильтруемости отличается не более чем на $2^{\circ} \mathrm{C}$ от таких же показателей у исходного топлива. Эти значения сравниваются с топливом до введения добавок, поэтому для применения таких подходов следует, как минимум иметь данные по исходному топливу и вводимым компонентам, что не всегда доступно, если процесс проходит на нефтебазе. Депрессорные присадки вводят в зимние и арктические дизельные топлива. Такие присадки с рабочими концентрациями 0,02-0,04\% вводят только в топлива, выработку которых невозможно осуществить путем подбора компонентного и фракционного состава, При длительном холодном хранении ДТ с присадкой происходит разделение на нижний слой, обогащенный кристаллами парафина, и верхний светлый. Обычно вводят бифункциональный пакет: депрессор и диспергатор парафина. Диспергаторы обеспечивают седиментационную устойчивость дизельного топлива при холодном хранении. Каждый НПЗ выпускает уникальное по составу дизельное топливо, к которому подбирают оптимальную депрессорную и диспергирующую присадку, т.к. в отличие от противоизносных присадок и промоторов воспламенения, депрессорно-диспергирующие присадки не универсальны.

В практике обращения ДТ имеются требования, которые не всегда напрямую относятся к заводскому качеству и не прописаны в нормативной документации на товарное топливо, но которые должны учитываться.

1. ДТ характеризуются высокой электризуемостью, зависящей от их состава, содержания дисперсной фазы, скорости потока топлива при перекачке, природы, площади и вида поверхности соприкосновения. Показатель удельной электропроводности ДТ находится в пределах от 0 до 5 пСм/м и определяется по методу ASTM D 2624-09. Отечественными исследованиями установлено, что моющая присадка (на основе сукцинимида низкомоле- 
кулярного полиизобутилена), депрессорно-диспергирующие присадки (на основе сополимеров этилена с винилацетатом, алкиламидов олеиновой кислоты) увеличивают электропроводность ДТ. Влияние на удельную электропроводность ДТ происходит за счет содержания в них диспергатора. Противоизносные присадки (высшие карбоновые кислоты) и промоторы воспламенения (2-ЭГН) не оказывают влияния на удельную электропроводность ДТ. Добавление в ДТ Евро газойлей каткрекинга, висбрекинга и коксования приводит к повышению удельной электропроводности. В ЕС рекомендована норма не менее 50 пСм/м, во Франции минимум 150 пСм/м при $20^{\circ} \mathrm{C}$ и использование присадки Stadis 450, в пункте заправки $\geq 50$. При хранении топлив удельная электропроводность ДТ уменьшается. В РФ действует ГОСТ ISO 6297-2015 «Нефтепродукты. Топлива авиационные и дистиллятные. Определение удельной электропроводности»

2. В дизельных топливах, особенно содержащих дистилляты процессов глубокой переработки, при хранении и эксплуатации под действием растворенного кислорода накапливаются продукты окисления (гидропероксиды, спирты, альдегиды, карбоновые кислоты), которые вступают в реакции уплотнения с образованием высокомолекулярных соединений, смол, осадков, загрязняющих топливные фильтры двигателя.

3. В настоящее время в стандартах отсутствуют ограничительные требования к гранулометрии загрязнений. Чистота ДТ по ИСО 4406 совершенно новый показатель для обеспечением эксплуатационной устойчивости форсунок инжекторов. Класс чистоты поставляемого дизельного топлива может сильно различаться в зависимости от поставщика. Известны требования производителей дизельных двигателей к типовому классу чистоты поставляемого топлива как 22/20/18 ISO 4406, что является нежелательным. Допустимым уровнем в резервуаре дистрибьютора считается норма 18/16/13 (требования Всемирной топливной хартии 2013 года), в бортовом баке $15 / 13 / 10$, а при подаче на форсунку высокого давления 12/9/6. Вместе с тем требования Bosch составляют 11/8/6 на инжекторе.

4. Изменение к требованиям тонкости фильтрации. Современные инжекторы имеют жесткие допуски в диапазоне 2 мкм, поэтому 10 мкм топливные фильтры сегодня заменяются на фильтры 7, 5, и даже 2 мкм. Помутневшее ДТ (ULSD) топливо легко может пройти через фильтр 10 мкм, но часто может заблокировать фильтр 5 или 2 мкм. Рекомендуется ориентироваться на параметр СР, если автомобили используют 2 микронные фильтры. Для автомобилей, в которых присутствуют 10 мкм фильтры, предлагается ориентироваться на средние показатели между СР и СFРP.

5. Требования к чистоте керосина, используемого для коррекции низкотемпературных свойств, следует обеспечивать по ИСО 4406. В мире керосин в хранении имеет чистоту $18 / 16 / 14$, реально на $20 \%$ грязнее, а в РФ требования к керосину по ИСО 4406 не приняты.

6. В мировой практике изучаются источники образования отложений на форсунке инжектора.
Отмечается [3], что обобщение результатов анализа химических отложений из различных инжекторов с техническими проблемами позволяет классифицировать их по трем различным категориям:

1). Полимерный органический материал с родственными присадкам составами.

2). Продукты окисления топлива.

3). Натрий содержащие смеси, в т.ч.: а). Натриевое мыло б). Хлорид натрия.

Зарубежные исследования показали, что такие вещества-присадки как PIBCI связаны с появлением органических амидных лаковых отложений. Отмечается образование отложений при взаимодействии PIBCI в присутствии муравьиной и жирных кислот (из FAME или присадок на базе талловых жирных кислот).

Выводы

Анализ требований нормативных документов и данных отечественных и зарубежных публикаций по практике обращения современных дизельных топлив показывает о необходимости совершенствования нормативной документации в части разрешения и учета следующих проблем:

1.Существенно снизить уровень обводненности топлив при операциях с нефтепродуктами, что позволит исключить наличие неопределенности конфликта присадок при смешении топлив разных производителей в резервуаре нефтебазы (некоторые виды присадок имеют свойство «уходить» с водой);

2.Требования к чистоте дизельных топлив существенно ужесточились и требуют выработки приемлемых для отечественных условий решений;

3.Нейтрализация эффекта электризации ДТ;

4.Не все присадки, которые традиционно используются для обработки ДТ с низким содержанием серы совместимы или достаточно эффективны в применении к ультранизкосернистому ДТ.

5.Рекомендуемые комплексные решения поддержания требуемой чистоты при движении от производителя к потребителю предлагают следующее: в целях предотвращения загрязнений топлива рекомендуется производить очистку топлива фильтрацией после резервуара хранения(нефтебаза) при заливе в автоцистерну, при перекачке от одного оптового поставщика к другому (на выходе из резервуapa, на входе фильтр устанавливается перед насосом для защиты насоса), при выдаче топлива потребителю. Такая схема позволяет предотвращать загрязнения по все цепочке движения топлива и не перегружать бортовые топливные фильтры

\section{Список литературы:}

1.Зоря Е.И., Короленок А.М., Лощенкова О.В., Киташов Ю.Н.Основы ресурсосбережения при обороте углеводородов: учебник по направлению подготовки бакалавров 21.03. 01 «Нефтегазовое дело». - Москва: Макс Пресс, 2018. -640 с.

2.Зоря Е.И., Лощенкова О.В., О требованиях к чистоте современных топлив. Экологический вестник России, №1, 2017 г., стр. 28-32

3.Jorg Ullmann, Marion Geduldig, Heinz Stutzenberger, Robert Bosch GmbH, Diesel Systems, Rinaldo Caprotti, Graham Balfour, Dennis Hess Infineum. Effects of Fuel Impurities and Additive Interactions on the Formation of Internal Diesel Injector Deposits 